\title{
Endoscopic ultrasonography-guided freestyle rendezvous recanalization of a complete postoperative rectosigmoid anastomotic obstruction with a lumen-apposing metal stent
}

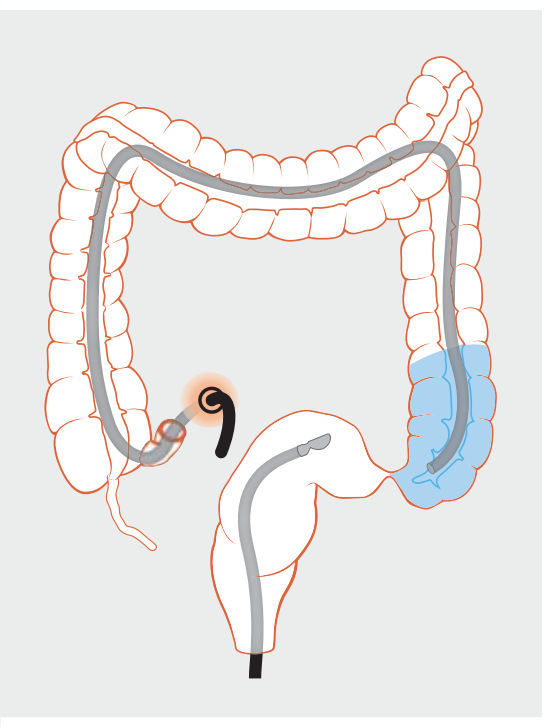

- Fig. 1 Schematic view showing the pediatric colonoscope and linear echoendoscope placed in the colon via the ileostomy and the rectum, respectively, and advanced towards the rectosigmoid obstruction.

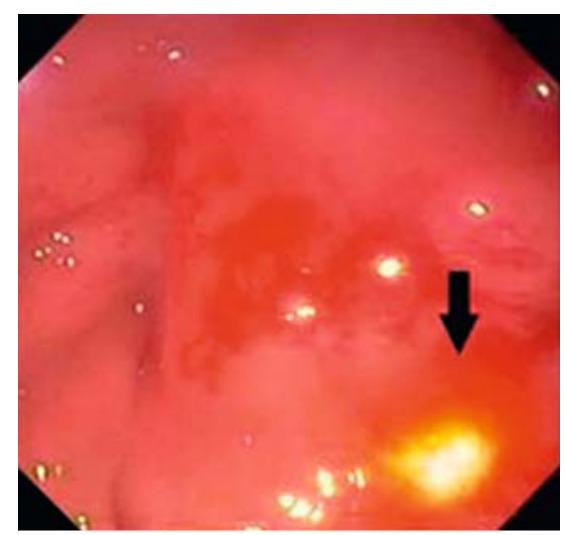

- Fig. 2 Endoscopic view showing transillumination from the pediatric colonoscope (arrow).

A 44-year-old woman with a large symptomatic uterine leiomyoma underwent radical pelvic mass resection, bilateral salpingo-oophorectomy, and modified pelvic exenteration with rectosigmoid resection and creation of a diverting

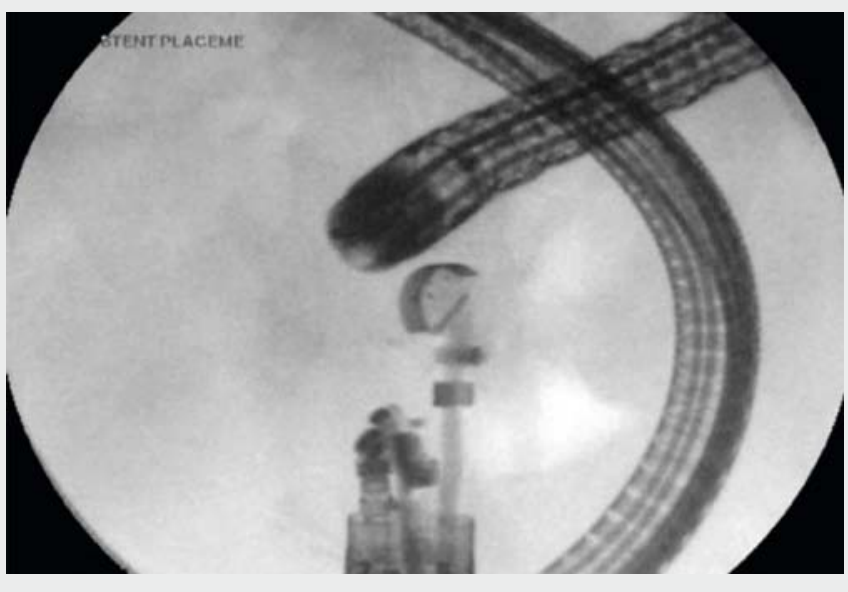

$\checkmark$ Video 1 A rendezvous approach is used to recanalize a postoperative rectosigmoid anastomotic obstruction with a lumen-apposing metal stent.

ileostomy. A sigmoidoscopy performed 2 months later followed by a water-soluble contrast enema showed complete obstruction of the rectosigmoid anastomosis. An endoscopic ultrasonography (EUS)-guided recanalization of the obstruction was planned.

A pediatric colonoscope was advanced through the ileostomy towards the sigmoid colon. Water was injected into the proximal side of obstruction to provide acoustic interface. A linear echoendoscope was then advanced through the rectum ( $>$ Fig. 1 ). The area of proximal colon was identified endoscopically by transillumination ( $\mathbf{F i g . 2}$ ) and endosonographically by detecting the fluid-filled lumen and the pediatric colonoscope. Under EUS guidance, the proximal colon was punctured with a cautery-enhanced lumen-apposing metal stent (LAMS; Axios, 15-mm diameter; Boston Scientific, Galway, Ireland). The proximal flange of the stent was deployed in the proximal colon and the distal flange was deployed in the rectal stump. The stent was then dilated with a controlled radial expansion balloon up to $15 \mathrm{~mm}$ ( $\mathbf{F i g . 3 a , b ) ; ~}$ - Video 1). The procedure was completed with no complications, and the patient was discharged home on the same day. At the 1 month follow-up, sigmoidoscopy was performed and the stent was found to have migrated distally. The anastomosis was patent, the stent was removed ( $\triangleright$ Fig. $\mathbf{3 c}$ ), and, 1 day later, ileostomy reversal was successfully performed. At her 10-month follow-up, the patient continued to report normal bowel movements with no residual symptoms.

In conclusion, EUS-guided recanalization of complete colorectal obstruction using a LAMS placed via the rendezvous technique was feasible and effective. In addition, freestyle deployment of a LAMS with a cautery tip facilitated an efficient procedure.

Endoscopy_UCTN_Code_TTT_1AQ_2AF 

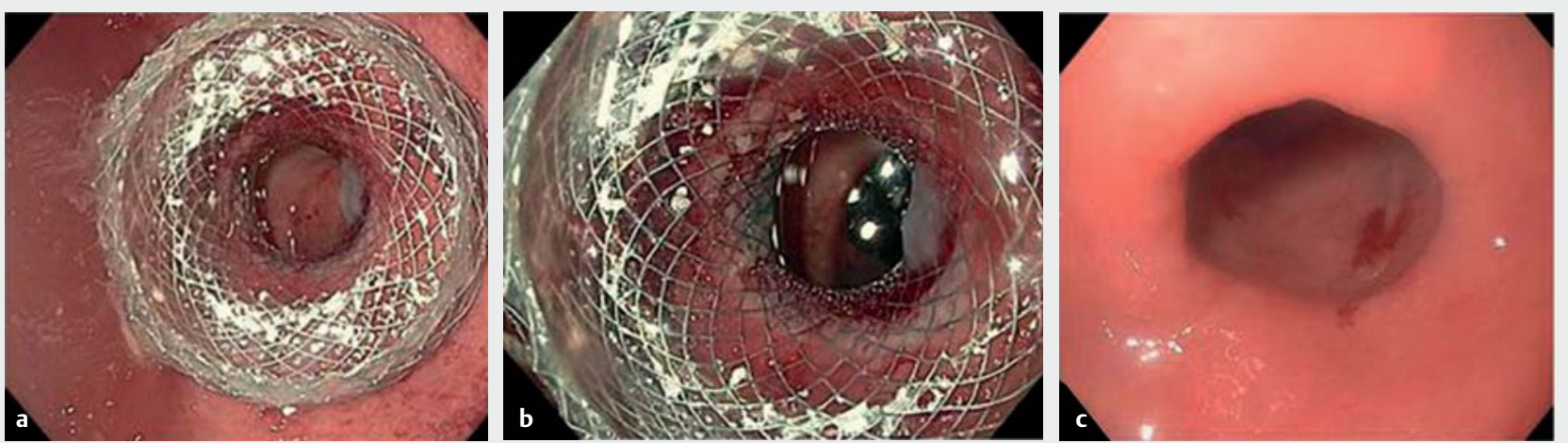

- Fig. 3 Endoscopic views showing: a the lumen-apposing metal stent after dilation; $\mathbf{b}$ the tip of the pediatric colonoscope visible through the dilated stent; $\mathbf{c}$ the patent anastomosis following stent removal.

\section{Competing interests}

Dr. Mouen A. Khashab is a consultant for Boston Scientific. Dr. Kumbhari is a consultant for Boston Scientific and Apollo Endosurgery. All other authors disclosed no financial relationships relevant to this publication.

The Authors

Omid Sanaei, Saowanee Ngamruengphong, Yen-I Chen, Majidah Bukhari, Olaya Brewer Gutierrez, Vivek Kumbhari, Mouen A.

\section{Khashab}

Division of Gastroenterology and Hepatology, Department of Medicine, Johns Hopkins Medical Institutions, Baltimore, Maryland, USA
Corresponding author

\section{Mouen A. Khashab, MD}

Johns Hopkins Hospital, Sheikh Zayed

Building, 1800 Orleans Street, Suite 7125G

Baltimore, MD 21287, USA

Fax: +1-443-683-8335

mkhasha1@jhmi.edu

\section{Bibliography}

DOI https://doi.org/10.1055/s-0043-104630

Published online: 29.6.2017

Endoscopy 2017; 49: E206-E207

(c) Georg Thieme Verlag KG

Stuttgart · New York

ISSN 0013-726X

\section{ENDOSCOPY E-VIDEOS}

https:|/eref.thieme.de/e-videos

回题 Endoscopy E-Videos is a free access online section, reporting 靣解: on interesting cases and new techniques in gastroenterological endoscopy. All papers include a high quality video and all contributions are freely accessible online.

This section has its own submission website at

https://mc.manuscriptcentral.com/e-videos 